\title{
Sarcopenia negatively affects hip structure analysis variables in a group of Lebanese postmenopausal women
}

Hayman Saddik ${ }^{1,2 \dagger}$, Riad Nasr ${ }^{1,3+}$, Antonio Pinti ${ }^{2,3^{*}}$, Eric Watelain ${ }^{4}$, Ibrahim Fayad ${ }^{1}$, Rafic Baddoura ${ }^{5}$, Abdel-Jalil Berro ${ }^{1,6}$, Nathalie Al Rassy ${ }^{7,8}$, Eric Lespessailles ${ }^{2}$, Hechmi Toumi $^{2}$ and Rawad El Hage ${ }^{1}$

From 6th International Work-Conference on Bioinformatics and Biomedical Engineering

Granada, Spain. 25-27 April 2018

\begin{abstract}
Background: The current study's purpose is to compare hip structural analysis variables in a group of postmenopausal women with sarcopenia and another group of postmenopausal women with normal skeletal muscle mass index. To do so, the current study included 8 postmenopausal women (whose ages ranged between 65 and 84 years) with sarcopenia and 60 age-matched controls (with normal skeletal muscle mass index (SMI)). Body composition and bone parameters were evaluated by dual-energy X-ray absorptiometry (DXA).

Results: Weight, lean mass, body mass index, femoral neck cross-sectional area (FN CSA), FN section modulus (Z), FN cross sectional moment of inertia (CSMI), intertrochanteric (IT) CSA, IT Z, IT CSMI, IT cortical thickness (CT), femoral shaft (FS) CSA, FS Z and FS CSMI were significantly greater $(p<0.05)$ in women with normal SMI compared to women with sarcopenia. In the whole population, SMI was positively associated with IT CSA, IT Z, IT CSMI, IT CT, FS CSA, FS Z, FS CSMI, FS CT but negatively correlated to IT buckling ratio (BR) and FS BR.

Conclusion: The current study suggests that sarcopenia has a negative effect on hip bone strength indices in postmenopausal women.
\end{abstract}

Keywords: Sarcopenia, DXA imaging, Bone strength indices, Fracture risk, Menopause

\section{Background}

In elderly humans, muscle mass decreases with age leading to "sarcopenia" or decreased muscle mass $[1,2]$. The life span of human beings has been steadily increasing in the past decades, and this has led to sarcopenia becoming more common; therefore, the impact of this disease on society is becoming more prevalent [3]. Lean mass is a major predictor of bone mineral density (BMD) and geometric indices of hip bone strength in elderly subjects [4-9]. In this population as well, fat mass is another determinant of BMD and geometric indices of hip bone strength [4-9]. Several studies have previously elucidated

\footnotetext{
*Correspondence: antonio.pinti@uphf.fr

${ }^{\dagger}$ Hayman Saddik and Riad Nasr contributed equally to this work.

${ }^{2}$ I3MTO, EA4708, Université d'Orléans, Orléans, France

${ }^{3}$ DeVisu - Design, Visuel, Urbain, EA 2445, UVHC, Valenciennes, France

Full list of author information is available at the end of the article
}

the mechanisms explaining the link between fat mass and bone parameters [4-9]. Lately, sarcopenia has been associated with low BMD values in the elderly [10, 11]. However, bone strength is influenced by both BMD and bone geometry [12-14]. Several studies have shown that hip structure analysis (HSA) variables can predict incident hip fracture risk in postmenopausal women [15-23]. In line with this, we have recently shown that sarcopenia has a negative effect on hip bone strength indices in elderly men [24]. On the contrary, in elderly women, the relationship between sarcopenia and hip bone strength indices has not been completely elucidated. The current study's purpose was to compare HSA variables in postmenopausal women with sarcopenia and postmenopausal women with normal skeletal muscle mass index. 


\section{Methods}

\section{Subjects and study design}

This study included 8 postmenopausal women (aged between 65 and 84 years; $71.6 \pm 4.7$ years) with sarcopenia and 60 age-matched (aged between 65 and 84years; $75.3 \pm 6.6$ years) controls (with normal skeletal muscle mass index). The women were randomly chosen from the greater Beirut area, Lebanon.

\section{Exclusion criteria}

The subjects that were excluded from the study were those suffering from any medical condition which could potentially affect bone metabolism such as history of chronic disease with vital organ involvement or intake of medications that may affect bone metabolism (i.e., steroid intake for more than 6 months and/or treatment with bone antiresorptive drugs). In addition, other subjects that were excluded were those with a radiotherapy or chemotherapy history or those who had been in bed rest for more than 1 month 6 months prior to the study. Other excluded subjects were those with conditions that technically interfere with dual-energy X-ray absorptiometry (DXA) assessment (i.e., previous spine or hip surgery). The Institutional Review Board of Hotel-Dieu Hospital, Saint Joseph University approved of this study, and all the subjects participating in it provided informed consent.

\section{Anthropometric measurements}

The subjects stood in an upright position for their height (in centimeters) to be measured to the nearest $1 \mathrm{~mm}$ with a Seca standard stadiometer (SecaGmbH, Hamburg, Germany). As for body weight, it was measured in kilograms on a Taurus mechanic scale with a precision of $100 \mathrm{~g}$. The women wore underclothes solely while being weighed. BMI was calculated as body weight divided by height squared (kilogram per square meter). Body composition was evaluated by DXA (HologicQDR-4500 W; Hologic Inc., Waltham, MA). In our medical center, the in vivo coefficients of variation were $<1 \%$ for fat and lean mass $[4,5]$.We used the skeletal muscle mass index (appendicular skeletal mass (ASM)/height ${ }^{2}$ ) to define sarcopenia as previously reported [1]. Based on DXA results, we calculated the ASM for each participant as the sum of the upper and lower limb muscle mass without fat and bone tissue. A skeletal muscle mass index $(\mathrm{SMI})<5.5 \mathrm{~kg} / \mathrm{m}^{2}$ for women was defined as the cut-off point for sarcopenia [1]. The European Working Group on Sarcopenia in Older People to define sarcopenia in women determined this cut-off point [2].

\section{Measurements of bone variables}

Dual-energy X-ray absorptiometry (Hologic QDR-4500 W, Waltham, MA USA) measurements were taken to evaluate bone mineral content (BMC) and bone mineral density (BMD). Both bone parameters were determined for each individual by DXA at whole body, lumbar spine and proximal femur (total hip [TH] and FN). In our laboratory, the coefficients of variation were $<1 \%$ for BMC and BMD [25-28]. All analyses were performed by the same certified technician who used the exact same technique for all measurements. The Hip Structure Analysis (HSA) program was used to assess hip strength indices by analyzing DXA scans at the femoral neck (FN), the intertrochanteric region (IT), and the femoral shaft (FS). The technical aspect of the HSA program was precisely explained in two previous studies $[11,12]$. In this study, we analyzed three regions of the hip: FN at its narrowest region, the IT region, and the FS. Bone CSA (in square centimeter) and $\mathrm{Z}$ (in cubic centimeter) were measured at the 3 regions as previously described $[11,12]$. Cross sectional area (CSA), which is an index of axial compression strength, section modulus (Z), which is an index of bending strength, cross sectional moment of inertia (CSMI), which is an index of structural rigidity, cortical thickness (CT), which is an estimate of mean cortical thickness, and buckling ratio (BR), which is an index of bone geometric instability, were measured by the HSA program [4, 12, 29]. Mechanically, CSA is a resistance indicator to loads directed along the bone axis. $\mathrm{Z}$ is a strength indicator of the bone which shows to what extent the bone can resist bending and torsion [29]. In this study, we also calculated BR, which is an index of susceptibility to local cortical buckling under compressive loads [29]. The buckling ratio is considered an estimate of relative cortical thickness (subperiosteal radius/cortical thickness). Higher Buckling Ratio values mean greater instability, and they are associated with increased fracture risk [30-33]. All HSA analyses were completed by one certified technician. In our medical center, the coefficients of variation for CSA and $\mathrm{Z}$ at the 3 regions (FN, IT, and FS) assessed by duplicate measurements in 10 women are $<3 \%$.

\section{Statistical analysis}

All clinical data and bone measurements had their standard deviations and means calculated. Gaussian distribution was checked when comparing the two groups (sarcopenic women and women with normal SMI). Parametric unpaired t-tests were used when Gaussian distribution was found. Mann-Whitney $U$ tests were used in other cases. Associations between clinical characteristics and DXA parameters were given as Pearson correlation coefficients. HSA variables were compared between the two groups (sarcopenic women and women with normal SMI) after adjustment for lean mass and body weight using a oneway analysis of covariance (ANCOVA). Data are analyzed with Number Cruncher Statistical System (NCSS, 2001). A level of significance of $p<0.05$ was used. 


\section{Results}

\section{Clinical characteristics and bone measurements of the} study population

Weight, body mass index, lean mass, fat mass, FN CSA, FN Z, FN CSMI, IT CSA, IT Z, IT CSMI, IT CT, FS CSA, FS Z and FS CSMI were significantly higher $(p<$ 0.05 ) in women with normal SMI compared to women with sarcopenia (Table 1). IT BR was significantly higher $(\mathrm{p}<0.05)$ in women with sarcopenia compared to women with normal SMI.

\section{Associations between body weight, lean mass, fat mass, SMI and hip structure analysis variables}

In the whole population (Table 2), body weight, lean mass and fat mass were positively correlated with CSA, CSMI, and CT at the FN, IT, and FS $(p<0.01)$ and negatively correlated with BR at the IT and FS $(p<0.01)$. SMI $\left(\mathrm{kg} / \mathrm{m}^{2}\right)$ was positively correlated to IT CSA ( $\mathrm{r}=0.30 ; p<0.05)$, IT Z $(\mathrm{r}=0.28 ; \mathrm{p}<0.05)$, IT CSMI $(\mathrm{r}=0.24 ; \mathrm{p}<0.05)$, IT CT $(\mathrm{r}=$ $0.29 ; \mathrm{p}<0.05)$, FS CSA $(\mathrm{r}=0.36 ; \mathrm{p}<0.01)$, FS $\mathrm{Z}(\mathrm{r}=0.36$; $\mathrm{p}<0.01)$, FS CSMI $(\mathrm{r}=0.32 ; \mathrm{p}<0.01)$, FS CT $(\mathrm{r}=0.32 ; \mathrm{p}<$ $0.01)$ but negatively correlated to IT BR $(\mathrm{r}=-0.31 ; \mathrm{p}<$ $0.05)$ and FS BR ( $r=-0.23$; $<<0.05)$ (Figs. 1 and 2).

\section{DXA adjusted variables}

After adjusting for lean mass using ANCOVA, no significant differences were observed between the two groups regarding all DXA parameters (WB BMC, WBBMD, L1-L4 BMD, TH BMD, FN BMD, FN CSA, FN CSMI, FN Z, IT CSA, IT CSMI, IT Z, IT CT, FS CSA, FS CSMI and FS Z).

After adjusting for body weight using ANCOVA, no significant differences were observed between the two groups regarding several DXA parameters (WB BMC, WBBMD, L1-L4 BMD, TH BMD, FN BMD, FN CSA,

Table 1 Clinical characteristics and bone variables in sarcopenic women and normal women

\begin{tabular}{|c|c|c|c|}
\hline & Women with normal SMI $(n=60)$ & Sarcopenic women $(n=8)$ & $P$-value \\
\hline Age (years) & $71.633 \pm 4.780$ & $75.375 \pm 6.610$ & 0.051 \\
\hline Weight (kg) & $70.233 \pm 12.500^{* *}$ & $55.875 \pm 9.141$ & 0.003 \\
\hline Height (m) & $1.519 \pm 0.0596$ & $1.504 \pm 0.0752$ & 0.503 \\
\hline BMI $\left(\mathrm{kg} / \mathrm{m}^{2}\right)$ & $30.343 \pm 4.745^{* *}$ & $24.653 \pm 3.059$ & 0.002 \\
\hline $\mathrm{FM}(\mathrm{kg})$ & $27.520 \pm 7.810^{*}$ & $20.578 \pm 6.490$ & 0.019 \\
\hline LM (kg) & $39.986 \pm 5.344^{* * *}$ & $31.236 \pm 2.827$ & $<0.001$ \\
\hline $\mathrm{SMI}\left(\mathrm{kg} / \mathrm{m}^{2}\right)$ & $7.22 \pm 1.40$ & $5.31 \pm 0.19$ & $<0.001$ \\
\hline WB BMD $\left(\mathrm{g} / \mathrm{cm}^{2}\right)$ & $0.884 \pm 0.0841$ & $0.834 \pm 0.0618$ & 0.106 \\
\hline WB BMC (kg) & $1.528 \pm 0.280^{*}$ & $1.285 \pm 0.202$ & 0.021 \\
\hline L1-L4 BMD $\left(\mathrm{g} / \mathrm{cm}^{2}\right)$ & $0.783 \pm 0.158$ & $0.746 \pm 0.0821$ & 0.827 \\
\hline TH BMD $\left(\mathrm{g} / \mathrm{cm}^{2}\right)$ & $0.727 \pm 0.124^{*}$ & $0.616 \pm 0.0894$ & 0.017 \\
\hline FN BMD $\left(\mathrm{g} / \mathrm{cm}^{2}\right)$ & $0.632 \pm 0.100^{* *}$ & $0.532 \pm 0.0871$ & 0.009 \\
\hline FN CSA $\left(\mathrm{cm}^{2}\right)$ & $2.214 \pm 0.405^{* *}$ & $1.821 \pm 0.212$ & 0.009 \\
\hline FN CSMI $\left(\mathrm{cm}^{2}\right)^{2}$ & $1.993 \pm 0.656^{*}$ & $1.408 \pm 0.261$ & 0.01 \\
\hline $\mathrm{FN} \mathrm{Z}\left(\mathrm{cm}^{3}\right)$ & $1.072 \pm 0.284^{*}$ & $0.801 \pm 0.159$ & 0.01 \\
\hline $\mathrm{FN} \mathrm{CT}(\mathrm{cm})$ & $0.140 \pm 0.034$ & $0.118 \pm 0.026$ & 0.08 \\
\hline FN BR & $13.92 \pm 2.94$ & $16.28 \pm 6.75$ & 0.08 \\
\hline IT CSA $\left(\mathrm{cm}^{2}\right)$ & $3.726 \pm 0.836^{* *}$ & $2.882 \pm 0.356$ & 0.007 \\
\hline IT CSMI $\left(\mathrm{cm}^{2}\right)^{2}$ & $9.36 \pm 3.05^{*}$ & $6.53 \pm 1.25$ & 0.01 \\
\hline IT Z $\left(\mathrm{cm}^{3}\right)$ & $3.090 \pm 0.879^{* *}$ & $2.208 \pm 0.399$ & 0.003 \\
\hline IT CT (cm) & $0.287 \pm 0.066^{*}$ & $0.231 \pm 0.034$ & 0.02 \\
\hline IT BR & $11.1 \pm 2.7^{*}$ & $13.1 \pm 2.6$ & 0.04 \\
\hline FS CSA $\left(\mathrm{cm}^{2}\right)$ & $3.520 \pm 0.647^{* *}$ & $2.853 \pm 0.343$ & 0.006 \\
\hline FS CSMI $\left(\mathrm{cm}^{2}\right)^{2}$ & $3.330 \pm 0.774^{* * *}$ & $2.350 \pm 0.363$ & $<0.001$ \\
\hline FS Z $\left(\mathrm{cm}^{3}\right)$ & $2.094 \pm 0.419^{* * *}$ & $1.516 \pm 0.237$ & $<0.001$ \\
\hline $\mathrm{FS} C \mathrm{CT}(\mathrm{cm})$ & $0.429 \pm 0.098$ & $0.360 \pm 0.068$ & 0.05 \\
\hline FS BR & $3.91 \pm 1.16$ & $4.53 \pm 1.34$ & 0.16 \\
\hline
\end{tabular}

BMI Body Mass Index, SMI Skeletal Muscle Mass Index, WB BMC Whole Body Bone Mineral Content, WB BMD Whole Body Bone Mineral Density, TH Total hip, FN Femoral Neck, FN CSA Femoral Neck Cross-Sectional Area, CSMI cross sectional moment of inertia, $Z$ Section modulus, CT Cortical Thickness, IT Intertrochanteric, FS Femoral shaft, $B R$ Buckling Ratio; ${ }^{*} p<0.05 ;{ }^{* *} p<0.01 ;{ }^{* * *} p<0.001$ 
Table 2 Correlations between body weight, lean mass, SMI and bone variables in the whole population

\begin{tabular}{|c|c|c|c|c|}
\hline & Body weight (kg) & Lean mass (kg) & Fat mass $(\mathrm{kg})$ & $\mathrm{SMI}\left(\mathrm{kg} / \mathrm{m}^{2}\right)$ \\
\hline WB BMC (g) & $0.720^{* *}$ & $0.581^{* *}$ & $0.673^{* *}$ & $0.295^{*}$ \\
\hline WB BMD $\left(\mathrm{g} / \mathrm{cm}^{2}\right)$ & $0.511^{* *}$ & $0.412^{* *}$ & $0.461^{* *}$ & $0.267^{*}$ \\
\hline L1-L4 BMD (g/ $\left.\mathrm{cm}^{2}\right)$ & $0.282^{*}$ & $0.243^{*}$ & $0.276^{*}$ & 0.090 \\
\hline TH BMD $\left(\mathrm{g} / \mathrm{cm}^{2}\right)$ & $0.649^{* *}$ & $0.503^{* *}$ & $0.663^{* *}$ & $0.323^{* *}$ \\
\hline FN BMD $\left(\mathrm{g} / \mathrm{cm}^{2}\right)$ & $0.533^{* *}$ & $0.455^{* *}$ & $0.505^{* *}$ & $0.258^{*}$ \\
\hline FN CSA $\left(\mathrm{cm}^{2}\right)$ & $0.512^{* *}$ & $0.519^{* *}$ & $0.449^{* *}$ & 0.218 \\
\hline FN CSMI $\left(\mathrm{cm}^{2}\right)^{2}$ & $0.359^{* *}$ & $0.435^{* *}$ & $0.280^{*}$ & 0.193 \\
\hline $\mathrm{FN} \mathrm{Z}\left(\mathrm{cm}^{3}\right)$ & $0.379^{* *}$ & $0.423^{* *}$ & $0.320^{* *}$ & 0.182 \\
\hline $\mathrm{FN} C \mathrm{CT}(\mathrm{cm})$ & $0.452^{* *}$ & $0.405^{* *}$ & $0.411^{* *}$ & 0.228 \\
\hline FN BR & -0.227 & -0.104 & $-0.271^{*}$ & -0.045 \\
\hline IT CSA $\left(\mathrm{cm}^{2}\right)$ & $0.641^{* *}$ & $0.600^{* *}$ & $0.589^{* *}$ & $0.308^{*}$ \\
\hline IT CSMI $\left(\mathrm{cm}^{2}\right)^{2}$ & $0.596^{* *}$ & $0.623^{* *}$ & $0.504^{* *}$ & $0.242^{*}$ \\
\hline IT Z $\left(\mathrm{cm}^{3}\right)$ & $0.609^{* *}$ & $0.631^{* *}$ & $0.511^{* *}$ & $0.287^{*}$ \\
\hline IT CT (cm) & $0.595^{* *}$ & $0.502^{* *}$ & $0.574^{* *}$ & $0.299^{*}$ \\
\hline IT BR & $-0.504^{* *}$ & $-0.380^{* *}$ & $-0.508^{* *}$ & $-0.309^{*}$ \\
\hline FS CSA $\left(\mathrm{cm}^{2}\right)$ & $0.689^{* *}$ & $0.635^{* *}$ & $0.664^{* *}$ & $0.361^{* *}$ \\
\hline FS CSMI $\left(\mathrm{cm}^{2}\right)^{2}$ & $0.642^{* *}$ & $0.716^{* *}$ & $0.555^{* *}$ & $0.322^{* *}$ \\
\hline $\mathrm{FS} Z\left(\mathrm{~cm}^{3}\right)$ & $0.688^{* *}$ & $0.717^{* *}$ & $0.626^{* *}$ & $0.364^{* *}$ \\
\hline $\mathrm{FS} C \mathrm{CT}(\mathrm{cm})$ & $0.590^{* *}$ & $0.479^{* *}$ & $0.599^{* *}$ & $0.329^{* *}$ \\
\hline FS BR & $-0.454^{* *}$ & $-0.288^{*}$ & $-0.516^{* *}$ & $-0.253^{*}$ \\
\hline
\end{tabular}

FN Femoral Neck, TH Total Hip, WB BMC Whole Body Bone Mineral Content, WB BMD Whole Body Bone Mineral Density, FN CSA Femoral Neck Cross-Sectional Area, CSMI cross sectional moment of inertia, Z Section modulus, CT Cortical Thickness, BR Buckling Ratio, IT Intertrochanteric, FS Femoral Shaft; ${ }^{*} p<0.05$; ** $p<0.01$

\section{Relation between SMI and FS Z}

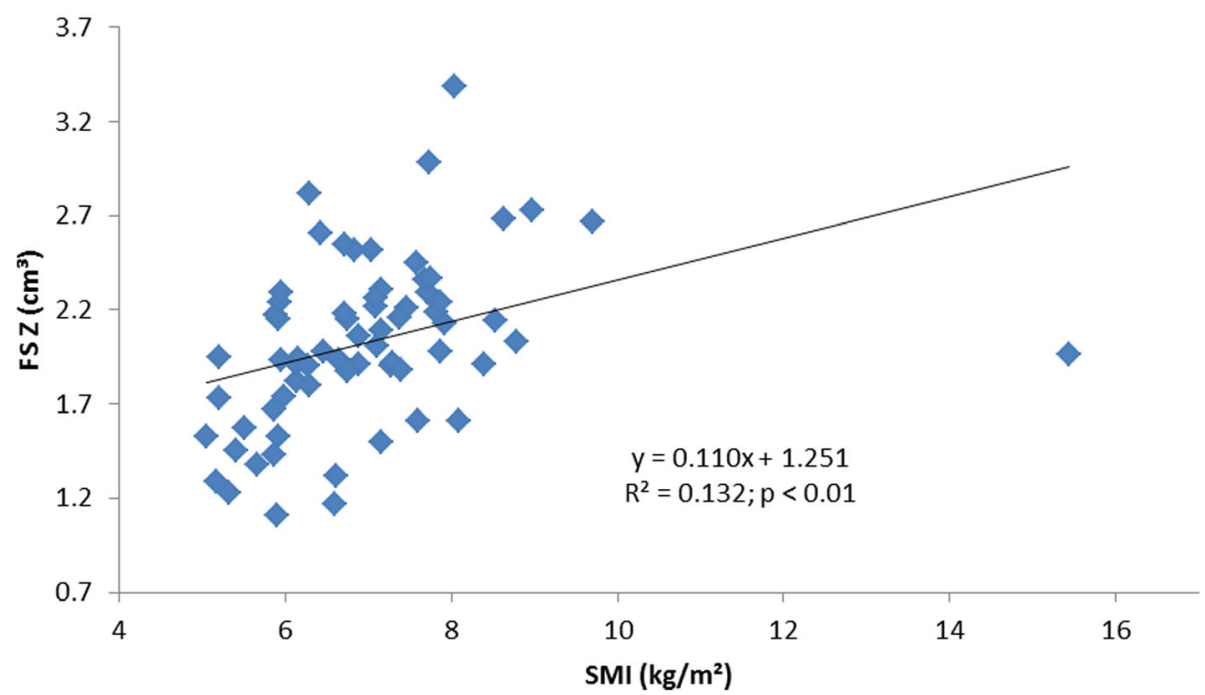

Fig. 1 Relation between skeletal muscle mass index and femoral shaft section modulus 


\section{Relation between SMI and FS CSA}

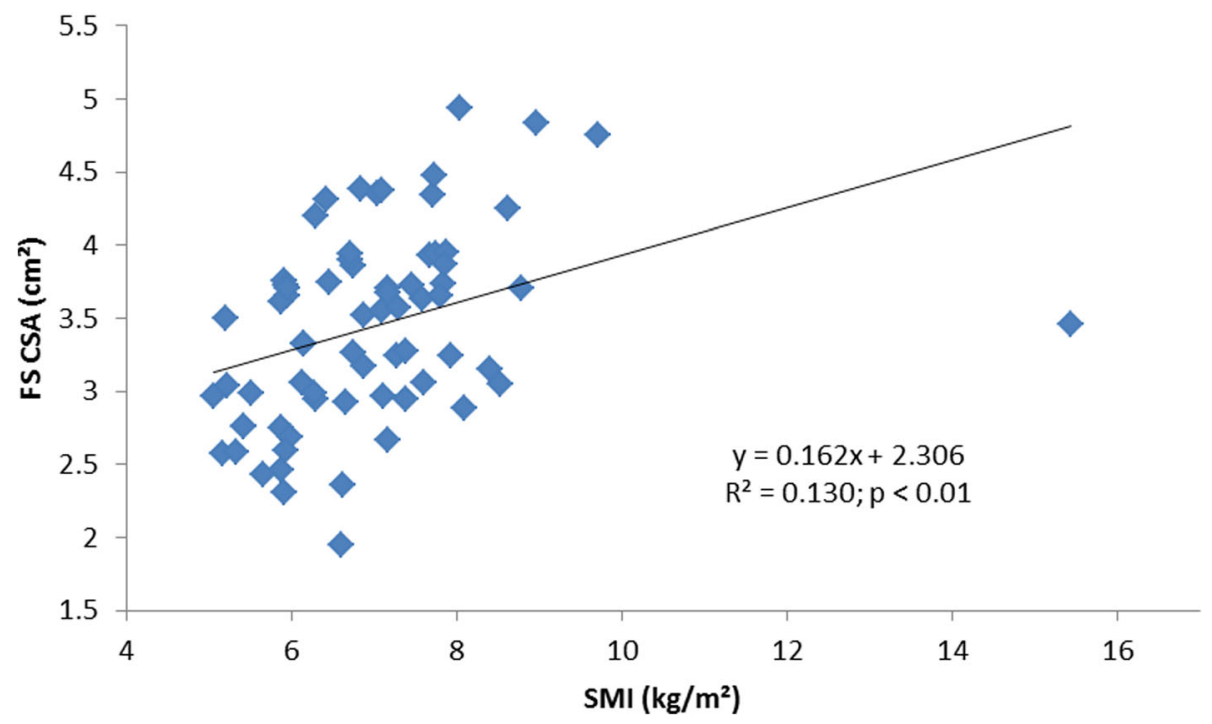

Fig. 2 Relation between skeletal muscle mass index and femoral shaft cross-sectional area

FN CSMI, FN Z, IT CSA, IT CSMI, IT Z, IT CT, FS CSA and FS CSMI) except for the FS $Z$ which remained significantly higher in non-sarcopenic women compared to sarcopenic women.

\section{Discussion}

This study which was conducted on a group of Lebanese post-menopausal women mainly demonstrates that sarcopenia is associated with lower geometric indices of hip bone strength. Moreover, the differences between the two groups (sarcopenic and non-sarcopenic women) regarding hip geometry indices disappeared after adjusting for lean mass. Thus, this study suggests that hip bone strength indices are adapted to lean mass in postmenopausal-women.

Weight, BMI, lean mass and fat mass were significantly higher in non-sarcopenic women compared to sarcopenic women. Sarcopenia is associated with significant changes in body weight and body composition which affect bone variables [34].

Lean mass and SMI were positive determinants of bone strength indices in our study. This result is in accordance with those of several studies conducted in elderly subjects [24, 35-38]. Higher SMI values correspond to higher dynamic loads imposed on bones [35-38]. These types of loads, known to activate an adaptive response, increase bone strength and decrease bone loss at an advanced age [35-38].

In our current study, the strongest determinants of bone variables were body weight and fat mass. Our results are in line with those of Reid et al. $[39,40]$ who demonstrated that fat mass is among the strongest determinants of BMD in menopausal women. In fact, fat mass may affect BMD by several mechanisms. The first mechanism is when increased fat mass raises mechanical loading on the skeleton [41]. Second, increased fat mass is associated with higher insulin, leptin, amylin and preptin circulating levels and lower adiponectin circulating levels [42]. Insulin, leptin, amylin and preptin have peripheral osteogenic effects via the stimulation of osteoblasts or the inhibition of osteoclasts while adiponectin enhances the osteoblast production of RANKL and constrains the production of osteoprotegerin (OPG) and is negatively correlated to BMD [43]. Third, free estrogen levels are increased in overweight and obese women [44, 45]. Fourth, another characteristic of fat mass is its ability to absorb environmental toxins thereby acting as a protector of other tissues in the body from the hazardous effects of those toxins [46-48]. Therefore, the larger the fat mass is, the lower the circulation of those environmental toxins will be; this will result in a decrease of the negative impact of these toxins on bone mass during the important bone formation years [46-48]. To sum up, age, gender and exercise status seem to influence the relationship between fat mass and bone mass $[5,9,49-51]$. For instance, fat mass excess is a risk factor for fracture in pre-pubertal children but protects against fracture in elderly [52].

In our study, sarcopenic women displayed lower hip BMD values compared to non-sarcopenic women. In addition, FN CSA, FN Z, FN CSMI, IT CSA, IT Z, IT CSMI, IT CT, FS CSA, FS Z and FS CSMI were significantly higher in women with normal SMI compared to women with sarcopenia while IT BR was significantly higher in women with sarcopenia compared to women with normal SMI. Higher buckling ratio values indicate 
greater cortical instability and thus increased risk of hip fracture $[23,29]$. These results suggest that sarcopenia is associated with lower bone strength at the hip in menopausal women. All these differences disappeared after adjusting for lean mass and most of these differences disappeared after adjusting for body weight. Thus, this study suggests that hip bone strength indices adapt properly to body weight and lean mass in menopausal women.

There were some limitations in the current study. First, the cross-sectional nature of the study was the reason for not having a good assessment of a causal mechanical relationship between SMI and hip strength variables. Second, our small sample size may be the reason behind the lack of statistical significance for some variables. Third, we did not assess endocrine factors which are well-known to have an impact on BMD in elderly women such as growth hormone, insulin-like growth factor 1, testosterone, estrogen, sex hormonebinding globulin and dehydroepiandrosterone. Fourth, we also did not evaluate other predictors of BMD and HSA indices like physical activity level, daily protein intake, daily calcium intake and vitamin D status. Finally, DXA cannot make a distinction between subcutaneous and visceral fat, or between subcutaneous and intramuscular peripheral fat; however, subcutaneous and visceral fat may have different effects on bone geometry and strength [53, 54]. Nevertheless, up to our knowledge, the current study is one among few others that has explored the effect of sarcopenia on hip strength indices in elderly women in the Middle-East region. Our results are in accordance with those of three recent studies that aimed at studying the relationships between sarcopenia and bone strength parameters [55-57].

\section{Conclusions}

This current study suggests that sarcopenia can negatively affect geometric indices of hip bone strength in postmenopausal women. Therefore, in order to prevent osteoporosis in postmenopausal women, implementing strategies to increase SMI is advised.

\footnotetext{
Abbreviations

ALM: Appendicular Lean Mass; ASM: Appendicular Skeletal Muscle Mass; BMC: Bone Mineral Content; BMD: Bone Mineral Density; BMl: Body Mass Index; BR: Buckling Ratio; CSA: Cross-Sectional Area; CSMI: Cross Sectional Moment of Inertia; CT: Cortical Thickness; FN: Femoral Neck; FS: Femoral Shaft; IT: Intertrochanteric; SMI: Skeletal Muscle Mass Index; TH: Total Hip; WB: Whole Body; Z: Section Modulus
}

\section{Acknowledgements}

Not applicable.

\section{About this supplement}

This article has been published as part of BMC Bioinformatics Volume 21 Supplement 2, 2020: Selected articles from the 6th International WorkConference on Bioinformatics and Biomedical Engineering. The full contents of the supplement are available online at URL.

\section{Authors' contributions}

$\mathrm{HS}$ and RN participated in the recruitment and data collection, analyzed the data and drafted the manuscript. EW, AP, IF, RB, AJB, HT, EL participated in the recruitment and data collection and revised the manuscript critically. NAR analyzed the data and revised the manuscript critically. AP and REH, participated in the study design, developed the protocol, and revised the manuscript. All authors read and approved of the final publication.

\section{Funding}

Nathalie Al Rassy is supported by a doctoral fellowship from the University of the Littoral Opal Coast (ULCO) and the National Council for Scientific Research of Lebanon (CNRS-L). Publication costs are not funded.

\section{Availability of data and materials}

The datasets used and/or analyzed during the current study are available from the corresponding author on reasonable request.

\section{Ethics approval and consent to participate}

"All procedures performed were in accordance with the ethical standards of the institutional and/or national research committee and with the 1964 Helsinki declaration and its later amendments or comparable ethical standards." The study was approved by the Institutional Review Board of Hotel-Dieu Hospital, Saint Joseph University, and informed consent was obtained from all study participants.

\section{Consent for publication}

Not applicable.

\section{Competing interests}

The authors declare that they have no competing interests.

\section{Author details}

'Department of Physical Education, University of Balamand, Kelhat, El-Koura, Lebanon. ${ }^{2}$ I3MTO, EA4708, Université d'Orléans, Orléans, France. ${ }^{3}$ DeVisu Design, Visuel, Urbain, EA 2445, UVHC, Valenciennes, France. ${ }^{4}$ Laboratoire Impact de l'Activité Physique sur la Santé (IAPS), Université de Toulon CS 60584- 83041 TOULON CEDEX 9, Toulon, France. ${ }^{5}$ Department of Rheumatology, Hôtel-Dieu Hospital, Saint Joseph University, Beirut, Lebanon. ${ }^{6} 6$ EA-3300, APERE, University of Picardie Jules Verne, Amiens, France. ${ }^{7}$ Laboratory of Pathophysiology of Inflammatory Bone Diseases PMOI EA4490, University of Littoral Opal Coast ULCO, Boulogne sur Mer, France.

${ }^{8}$ University of Lille, Lille, France.

Published: 13 March 2020

\section{References}

1. Baumgartner RN, Koehler KM, Gallagher D, Romero L, Heymsfield SB, Ross RR, et al. Epidemiology of sarcopenia among the elderly in New Mexico. Am J Epidemiol. 1998;147:755-63.

2. Cruz-Jentoft A, Baeyens JP, Bauer JM, Boirie Y, Cederholm T, Landi F, et al. Sarcopenia: European consensus on definition and diagnosis: report of the European working group on sarcopenia in older people. Age Ageing. 2010;39:412-23.

3. Morley JE, Abbatecola AM, Argiles JM, Baracos V, Bauer J, Bhasin S, et al. Sarcopenia with limited mobility: an international consensus. J Am Med Dir Assoc. 2011;12:403-9.

4. El Hage R, Theunynck D, Rocher E, Baddoura R. Geometric indices of hip bone strength in overweight and control elderly men. J Med Liban. 2014;62:150-5.

5. El Hage R, Mina F, Ayoub M-L, Theunynck D, Baddoura R. Relative importance of lean mass and fat mass on bone mineral density in a group of Lebanese elderly men. J Med Liban. 2012;60:136-41.

6. Taaffe DR, Villa ML, Holloway L, Marcus R. Bone mineral density in older non-Hispanic Caucasian and Mexican-American women: relationship to lean and fat mass. Ann Hum Biol. 2000;27:331-44.

7. Chiu GR, Araujo AB, Travison TG, Hall SA, McKinlay JB. Relative contributions of multiple determinants to bone mineral density in men. Osteoporos Int. 2009;20:2035-47.

8. Beck TJ, Petit MA, Wu G, LeBoff MS, Cauley JA, Chen Z. Does obesity really make the femur stronger? BMD, geometry, and fracture incidence in the women's health initiative-observational study. J Bone Miner Res. 2009;24:1369-79. 
9. Travison TG, Araujo AB, Esche GR, Beck TJ, McKinlay JB. Lean mass and not fat mass is associated with male proximal femur strength. J Bone Miner Res. 2008;23:189-98.

10. Edwards $M H$, Dennison EM, Aihie Sayer A, Fielding R, Cooper C. Osteoporosis and sarcopenia in older age. Bone. 2015;80:126-30.

11. Pereira FB, Leite AF, de Paula AP. Relationship between pre-sarcopenia, sarcopenia and bone mineral density in elderly men. Arch Endocrinol Metab. 2015;59:59-65.

12. Beck TJ, Ruff CB, Warden KE, Scott WW, Rao GU. Predicting femoral neck strength from bone mineral data. A structural approach. Investig Radiol. 1990;25:6-18.

13. Beck TJ, Broy SB. Measurement of hip geometry-technical background. J Clin Densitom. 2015;18:331-7.

14. Bouxsein ML, Karasik D. Bone geometry and skeletal fragility. Curr Osteoporos Rep. 2006;4:49-56.

15. LaCroix AZ, Beck TJ, Cauley JA, Lewis CE, Bassford T, Jackson R, et al. Hip structural geometry and incidence of hip fracture in postmenopausal women: what does it add to conventional bone mineral density? Osteoporos Int. 2010;21:919-29.

16. Reider L, Beck TJ, Hochberg MC, Hawkes WG, Orwig D, YuYahiro JA, et al. Women with hip fracture experience greater loss of geometric strength in the contralateral hip during the year following fracture compared to agematched controls. Osteoporos Int. 2010;21:741-50.

17. Kaptoge S, Beck TJ, Reeve J, Stone KL, Hillier TA, Cauley JA, et al. Prediction of incident hip fracture risk by femur geometry variables measured by hip structural analysis in the study of osteoporotic fractures. J Bone Miner Res. 2008;23:1892-904

18. Melton $L$, Beck TJ, Amin S, Khosla S, Achenbach SJ, Oberg AL, et al. Contributions of bone density and structure to fracture risk assessment in men and women. Osteoporos Int. 2005;16:460-7.

19. Szulc P, Duboeuf F, Schott AM, Dargent-Molina P, Meunier PJ, Delmas PD. Structural determinants of hip fracture in elderly women: re-analysis of the data from the EPIDOS study. Osteoporos Int. 2006;17:231-6.

20. Leslie WD, Pahlavan PS, Tsang JF, Lix LM, Program MBD. Prediction of hip and other osteoporotic fractures from hip geometry in a large clinical cohort. Osteoporos Int. 2009;20:1767-74.

21. El-Kaissi S, Pasco JA, Henry MJ, Panahi S, Nicholson JG, Nicholson GC, et al. Femoral neck geometry and hip fracture risk: the Geelong osteoporosis study. Osteoporos Int. 2005;16:1299-303.

22. Crabtree NJ, Kroger H, Martin A, Pols HAP, Lorenc R, Nijs J, et al. Improving risk assessment: hip geometry, bone mineral distribution and bone strength in hip fracture cases and controls. The EPOS study. European prospective osteoporosis study. Osteoporos Int. 2002;13:48-54.

23. Ahlborg HG, Nguyen ND, Nguyen TV, Center JR, Eisman JA. Contribution of hip strength indices to hip fracture risk in elderly men and women. J Bone Miner Res. 2005;20:1820-7.

24. Nasr R, Watelain E, Pinti A, Maalouf G, Berro A-J, El Hage R. Sarcopenia and hip structure analysis variables in a group of elderly men. J Clin Densitom. 2018;21:312-3

25. El Hage R, Bachour F, Khairallah W, Bedran F, Maalouf N, Zakhem E, et al. The influence of obesity and overweight on hip bone mineral density in Lebanese women. J Clin Densitom. 2014;17:216-7.

26. El Hage R, Khairallah W, Bachour F, Issa M, Eid R, Fayad F, et al. Influence of age, morphological characteristics, and lumbar spine bone mineral density on lumbar spine trabecular bone score in Lebanese women. J Clin Densitom. 2014;17:434-5.

27. Zakhem E, Ayoub M-L, Zunquin G, Theunynck D, Bedran F, Sebaaly A, et al. Physical performance and trabecular bone score in a group of young Lebanese women. J Clin Densitom. 2015;18:271-2.

28. El Hage R, Zakhem E, Theunynck D, Zunquin G, Bedran F, Sebaaly A, et al. Maximal oxygen consumption and bone mineral density in a group of young Lebanese adults. J Clin Densitom. 2014;17:320-4.

29. Beck TJ. Extending DXA beyond bone mineral density: understanding hip structure analysis. Curr Osteoporos Rep. 2007:5:49-55.

30. Anitha D, Lee T. Assessing bone quality in terms of bone mineral density, buckling ratio and critical fracture load. J Bone Metab. 2014;21:243-7.

31. Sheu Y, Cauley JA, Patrick AL, Wheeler WW, Bunker CH, Zmuda JM. Risk factors for fracture in middle- and older-age men of African descent. J Bone Miner Res. 2014;29:234-41.

32. Duan Y, Beck TJ, Wang X-F, Seeman E. Structural and biomechanical basis of sexual dimorphism in femoral neck fragility has its origins in growth and aging. J Bone Miner Res. 2003;18:1766-74.
33. Kaptoge S, Dalzell N, Loveridge N, Beck TJ, Khaw K-T, Reeve J. Effects of gender, anthropometric variables, and aging on the evolution of hip strength in men and women aged over 65. Bone. 2003;32:561-70.

34. Evans WJ, Campbell WW. Sarcopenia and age-related changes in body composition and functional capacity. J Nutr. 1993;123(2 Suppl):465-8.

35. Blain H, Jaussent A, Thomas E, Micallef J-P, Dupuy A-M, Bernard PL, et al. Appendicular skeletal muscle mass is the strongest independent factor associated with femoral neck bone mineral density in adult and older men. Exp Gerontol. 2010;45:679-84.

36. Szulc P, Beck TJ, Marchand F, Delmas PD. Low skeletal muscle mass is associated with poor structural parameters of bone and impaired balance in elderly men--the MINOS study. J Bone Miner Res. 2005;20:721-9.

37. Hong W, Cheng Q, Zhu X, Zhu H, Li H, Zhang X, et al. Prevalence of sarcopenia and its relationship with sites of fragility fractures in elderly chinese men and women. PLoS One. 2015;10:e0138102.

38. Hong S, Choi WH. The effects of sarcopenia and obesity on femur neck bone mineral density in elderly Korean men and women. Osteoporos Sarcopenia. 2016;2:103-9.

39. Reid IR. Relationships between fat and bone. Osteoporos Int. 2008;19:595-606.

40. Reid IR, Ames R, Evans MC, Sharpe S, Gamble G, France JT, et al. Determinants of total body and regional bone mineral density in normal postmenopausal women--a key role for fat mass. J Clin Endocrinol Metab. 1992;75:45-51.

41. Iwaniec UT, Turner RT. Influence of body weight on bone mass, architecture and turnover. J Endocrinol. 2016;230:R115-30.

42. Cornish J, Costa JL, Naot D. The bone-fat mass relationship: laboratory studies. IBMS BoneKEy. 2009:6:311-22.

43. Naot D, Cornish J. Cytokines and Hormones That Contribute to the Positive Association between Fat and Bone. Front Endocrinol (Lausanne). 2014;5. https://doi.org/10.3389/fendo.2014.00070.

44. Shapses SA, Sukumar D. Bone metabolism in obesity and weight loss. Annu Rev Nutr. 2012;32:287-309.

45. Zhao L-J, Jiang H, Papasian CJ, Maulik D, Drees B, Hamilton J, et al. Correlation of obesity and osteoporosis: effect of fat mass on the determination of osteoporosis. J Bone Miner Res. 2008;23:17-29.

46. Cho M-R, Shin J-Y, Hwang J-H, Jacobs DR, Kim S-Y, Lee D-H. Associations of fat mass and lean mass with bone mineral density differ by levels of persistent organic pollutants: National Health and nutrition examination survey 1999-2004. Chemosphere. 2011;82:1268-76.

47. Van der Ven LTM, Van de Kuil T, Leonards PEG, Slob W, Lilienthal H, Litens S, et al. Endocrine effects of hexabromocyclododecane (HBCD) in a onegeneration reproduction study in Wistar rats. Toxicol Lett. 2009;185:51-62.

48. Lind PM, Milnes MR, Lundberg R, Bermudez D, Orberg JA, Guillette L. Abnormal bone composition in female juvenile American alligators from a pesticide-polluted lake (Lake Apopka, Florida). Environ Health Perspect. 2004;112:359-62.

49. Reid IR. Fat and bone. Arch Biochem Biophys. 2010;503:20-7.

50. Reid IR. Relationships among body mass, its components, and bone. Bone. 2002;31:547-55

51. Wang MC, Bachrach LK, Van Loan M, Hudes M, Flegal KM, Crawford PB. The relative contributions of lean tissue mass and fat mass to bone density in young women. Bone. 2005;37:474-81.

52. Dimitri P, Bishop N, Walsh JS, Eastell R. Obesity is a risk factor for fracture in children but is protective against fracture in adults: a paradox. Bone. 2012;50:457-66.

53. Bolotin $\mathrm{HH}$, Sievänen $\mathrm{H}$. Inaccuracies inherent in dual-energy $\mathrm{X}$-ray absorptiometry in vivo bone mineral density can seriously mislead diagnostic/prognostic interpretations of patient-specific bone fragility. J Bone Miner Res. 2001;16:799-805.

54. Gilsanz V, Chalfant J, Mo AO, Lee DC, Dorey FJ, Mittelman SD. Reciprocal relations of subcutaneous and visceral fat to bone structure and strength. J Clin Endocrinol Metab. 2009:94:3387-93.

55. Choi H, Yoo Jl. Sarcopenia and hip-structure analysis variables in Korean elderly population. J Clin Densitom. 2018; In press.

56. Oliveira A, Vaz C. The role of sarcopenia in the risk of osteoporotic hip fracture. Clin Rheumatol. 2015;34(10):1673-80.

57. Di Monaco M, Castiglioni C, De Toma E, Gardin L, Giordano S, Di Monaco R, Tappero R. Presarcopenia and sarcopenia in hip-fracture women: prevalence and association with ability to function in activities of daily living. Aging Clin Exp Res. 2015;27(4):465-72.

\section{Publisher's Note}

Springer Nature remains neutral with regard to jurisdictional claims in published maps and institutional affiliations. 